Das glaubte ich als eine Andeutung nehmen zu dürfen für die Veränderlichkeit des Spaltungsproducts.

Gewifs scheint mir nach Allem, dafs die Verhandlungen über diese Stoffe noch nicht als geschlossen angesehen werden dürfen.

Ueber das Vorkommen von Propylamin in den Blüthen von Crataegus oxyacantha;

von Dr. Wilh. Wicke.

Die Blüthen von Crataegus oxyacantha haben einen eigenthümlichen, an faule Fische erinnernden Geruch. Derselbe haftet stundenlang an den Fingern, und tritt am Deutlichsten beim Zerquetschen der frisch aufgebrochenen Blüthen hervor. Schon im letzten Frühjahr machte ich einen Versuch, ob vielleicht Propylamin aus den Blüthen zu erhalten seyn möchte, konnte aber damals keine für eine quantitative Bestimmung hinreichende Menge Blüthen bekommen.

Inzwischen hat Wittstein (dessen Vierteljabresschr. Il, 402) dieselbe Beobachtung gemacht. Er wandte zu seiner Untersuchung 6 Unzen Blüthen (von Pyrus communis) an, die er mit verdünnter Kalilauge destillirte. Aus dem Destillate stellte er 1 Gran des schwefelsauren Salzes dar, welches er nur an dem Merkmal, dafs es mit Kalilauge einen penetranten Häringsgeruch entwickelte, als schwefelsaures Propylamin erkannte. In den Blüthen von Crataegus monogyna und Sorbus aucuparia ist nach Wittstein ebenfalls Propylamin enthalten.

Immerhin schien mir noch eine quantitative Bestimmung nothwendig zu seyn, um mit Gewifsheit die Gegenwart von Propylamin zu constatiren. Zu dem Ende wurden mehrere 
Pfunde der Blüthen gleich nach dem Aufblühen eingesammelt, zerquetscht und mit verdünter Natronlauge destillirt. Das zuerst Uebergehende zeigte den bekannten Geruch am stärkslen. Das Destilliren wurde so lange fortgesetzt, als das Destillat noch deutlich alkalische Reaction zeigte. Dasselbe wurde dann mit Salzsäure neutralisirt und im Wasserbade zur Trockne verdunstet. Die erhaltene Salzmasse wurde mit Aether-Alkohol digerirt, filtrirt und das Filtrat mit Platinchlorid versetzt. Es fiel ein hellgelbes krystallinisches Pulver.

$0,1505 \mathrm{Grm}$. des Platinsalzes wurden in einem Porcellantiegel durch Glühen zersetzt. Erhalten wurden 0,0558 Gran Platin. Diese entsprechen $37,2 \mathrm{pC}$. Platin, welche mit der berechneten Menge Platin zusammenfallen.

Mehr noch als in den Bluthen ist in den weiter entwickelten Knospen das Propylamin enthalten. Während des Blühens verdunstet es allmälig, so dafs die älteren Blüthen den Geruch fast gar nicht mehr zeigen. Es soll nach Wittstein als eine Art Secret aus dem Blüthenboden ausschwitzen.

\section{Ueber die Bildungs - und Bereitungsweise des}

\section{Aethylamins ;}

von Dr. A. Göfsmann,

Assistent am chemischen Laboratorium zu Göttingen.

Bei Versuchen über das Aldehyd - Ammoniak beschäftigte ich mich auch mit der von Redtenbacher*) entdeckten, mit dem Taurin isomeren Verbindung desselben mit schwefliger Säure, und fand, dafs sie beim Erhitzen mit Kalk ein ammoniakalisch riechendes und dabei brennbares Gas ent-

*) Diese Annalen LXV, 37. 